\title{
Selective Blockade of the Mineralocorticoid Receptor Impairs Hypothalamic-Pituitary-Adrenal Axis Expression of Habituation
}

\author{
M. A. Cole, B. A. Kalman, T. W. W. Pace, F. Topczewski, M. J. Lowrey and R. L. Spencer \\ Department of Psychology, University of Colorado, Boulder, CO, USA. \\ Key words: RU40555, RU28318, stress, rat, corticosterone.
}

\begin{abstract}
The present study investigated the role of mineralocorticoid receptors (MR) and glucocorticoid receptors (GR) in the expression of habituation of the hypothalamic-pituitary-adrenal (HPA) axis response to stress. Male rats were restrained for $1 \mathrm{~h}$ per day for six consecutive days. On day $6,1 \mathrm{~h}$ prior to restraint stress, both restraint-naive and repeatedly restrained rats were injected s.c. with either vehicle (propylene glycol) or one of three corticosteroid receptor antagonist treatments: selective MR antagonist (RU28318 or spironolactone), selective GR antagonist (RU40555), or both MR and GR antagonists combined (RU28318 + RU40555). Blood samples were collected for corticosterone measurement at the beginning of stress, during stress, and $1 \mathrm{~h}$ after stress termination. Repeated restraint stress produced significant habituation of corticosterone responses. Acute treatment with the combined MR and GR antagonists prevented the expression of habituation. When tested alone, the MR antagonist also blocked the expression of corticosterone-response habituation, whereas the GR antagonist had no effect. Neither the MR, nor the GR antagonists alone, significantly altered the corticosterone response to restraint in rats exposed to restraint for the first time. The final experiment examined the corticosterone response to a corticotropin releasing hormone $(\mathrm{CRH}, 3 \mu \mathrm{g} / \mathrm{kg}$ i.p.) challenge. Neither previous exposure to restraint or acute pretreatment with the combined MR and GR antagonists (RU28318 + RU40555) altered the corticosterone response to $\mathrm{CRH}$ challenge. This result indicates that the expression of habituation and its blockade by corticosteroid receptor antagonists is not a result of altered pituitary-adrenal response to $\mathrm{CRH}$. Overall, this study suggests that MR plays an important role in constraining the HPA axis response to restraint stress in restraint-habituated rats. The dependence of the HPA axis on MR-mediated corticosteroid negative feedback during acute stress may be an important mechanism that helps maximize the expression of stress habituation and thereby minimize exposure of target tissues to corticosteroids in the context of repeated stress.
\end{abstract}

Repeated exposure to stress often leads to adaptation within stress response systems that is evident by a change in the magnitude of subsequent elicited stress responses. In some cases, repeated stress leads to an enhanced or sensitized stress response and in other cases it leads to a blunted or habituated stress response $(1,2)$. Although some of the conditions that lead to stress response sensitization or habituation have been characterized, there is very little understanding of the mechanisms responsible for this adaptation. We have studied a stress habituation paradigm in which rats were repeatedly exposed to restraint stress. Our studies focused on the hypothalamic-pituitary-adrenal (HPA) axis as a stress response system by which to monitor the habituation process $(3,4)$. For the studies reported here, we considered the possibility that corticosterone negative feedback plays an important role in the expression of HPA axis response habituation.

Two intracellular corticosteroid receptor types were identified (5-7) which participate in corticosteroid negative feedback (8). One receptor type, the mineralocorticoid receptor (MR or type I), has a high affinity for corticosteroids and is believed to be predominantly occupied (greater than $70-90 \%$ ) by corticosterone even under resting conditions during the circadian trough $(7,9)$. The second receptor type, the

Correspondence to: Robert L. Spencer, Department of Psychology, Campus Box 345, University of Colorado, Boulder, CO 80309, USA (e-mail: spencer@psych.colorado.edu). 
glucocorticoid receptor (GR or type II), has a lower affinity for corticosteroids. Only during periods of high circulating corticosteroids, such as during stress or the circadian peak, do GR become substantially occupied $(7,10)$.

Functional differences between MR and GR in mediating corticosteroid feedback inhibition have been determined in part by the utilization of selective MR and GR antagonists $(11,12)$. In a previous study, we found that acute treatment of rats with the selective MR antagonist, RU28318, produced elevated basal corticosterone levels in the circadian trough, but not during the circadian peak (13). In addition, the MR antagonist did not alter corticosterone secretion in response to restraint stress administered during either the circadian trough or peak. Weidenfeld and Feldman (12) also observed no effect of RU28318 treatment on acute stress, although Ratka et al. (11) found that RU28318 treatment led to sustained stress levels of corticosterone after exposure to a novel environment. With respect to studies blocking GR, we found that the selective GR antagonist RU40555 (14) had no effect on basal or restraint stress corticosterone levels (13). Another GR antagonist, RU38486, was found by others to interfere with corticosteroid negative feedback during stress $(11,12)$. The discrepancy between the effects of these two GR antagonists may be due to the dose of RU40555 used in our study. Due to limited solubility, RU40555 appears to occupy approximately $50 \%$ of GR $(13,14)$, whereas the dose of RU38486 used by others may occupy a significantly higher percentage of GR. In the only study to block both MR and GR during stress, we found that combined treatment with RU28318 and RU40555 produced an elevation of basal and stress corticosterone levels (13). These studies and others support the belief that MR maintains low basal activity of the HPA axis during the circadian trough $(8,15,16)$ and that $G R$, with facilitation by MR, constrains the increased HPA axis activity present during the circadian peak and during acute stress $(13,17,18)$.

Although these studies provide important insights into the role of corticosteroid feedback in the daily operation of the HPA axis, the role of corticosteroid feedback in the habituation of the HPA axis to repeated or chronic stress remains unclear. It has yet to be determined whether habituation of the HPA axis is dependent on corticosterone negative feedback. At a systems level, habituation of the HPA axis response to repeated stress must be a result of at least one of the following changes in the system's response to acute stress: (i) there is a change in the neural input to the axis, such that there is a decreased excitatory input or there is an increased inhibitory input, and/or (ii) there is a change in the response of the axis to neural input, such that there is a decreased response to excitatory input or there is an increased response to inhibitory input. Corticosteroid negative feedback may modulate both the neural input to the HPA axis (indirect negative feedback) and how the axis responds to that neural input (direct negative feedback) (8). Thus, corticosteroids may be an important contributor to the ability of the HPA axis to express habituation. To test this prospect, we investigated the role of both MR and GR activation in the ability of the HPA axis to express habituation to repeated restraint stress in rats. MR antagonists (RU28318 or spironolactone) and the GR antagonist (RU40555) were administered individually or simultaneously (RU28318 + RU40555) to restraint naive or restraint habituated rats. Additionally, we used $\mathrm{CRH}$ challenge in combination with corticosteroid receptor antagonists to determine if habituation involves a change in pituitary sensitivity to $\mathrm{CRH}$, or a change in corticosteroid negative feedback sensitivity at the level of the pituitary.

\section{Materials and methods}

\section{Subjects}

Subjects were young adult, male Sprague-Dawley rats supplied from Harlan Sprague-Dawley (Indianapolis, IN, USA) with weights ranging from 250-350 g. Rats were housed in hanging wire mesh cages (two or three per cage) and were maintained on a 12-h light-dark cycle (lights on at $07.00 \mathrm{~h}$ ). After arrival at the University of Colorado animal facilities, rats were allowed 2 weeks to acclimate to their home cages. Rat chow and water were provided ad libitum. All treatments and blood samples took place during the first half of the light period. All procedures were approved by the University of Colorado's Animal Care and Use Committee.

\section{Glucocorticoid and mineralocorticoid receptor antagonist treatment}

The glucocorticoid receptor antagonist, RU40555, and the mineralocorticoid antagonist, RU28318, were donated by Roussel Uclaf (now Hoescht Marion Roussel; Romainville, France). The mineralocorticoid receptor antagonist, spironolactone, was purchased from Sigma (St Louis, MO, USA). The doses of RU40555 (30 mg/kg) and RU28318 (50 mg/kg) used were based on previous evaluation where functional studies and receptor binding assays demonstrated selective antagonism of the glucocorticoid and mineralocorticoid receptors, respectively $(13,14)$. RU28318 was found to occupy almost $100 \%$ of available MR. Although the dose of RU40555 used in these studies appears to only occupy approximately $50 \%$ of available GR, we have found that this dose completely blocked dexamethasone $(50 \mu \mathrm{g} / \mathrm{kg}$ s.c.) suppression of stressinduced corticosterone secretion (14). Due to poor solubility of RU40555, we were not able to use higher doses of this drug. Both RU40555 and RU28318 were dissolved in propylene glycol and the injections were given s.c. $(3 \mathrm{ml} / \mathrm{kg})$. For combined MR and GR antagonist treatment, the drugs were dissolved together into a single antagonist cocktail solution. For vehicle treatment, rats were given an equal volume s.c. injection of propylene glycol. In experiment 5, spironolactone was used as an alternative mineralocorticoid receptor antagonist (19). The dose used was based on pilot studies examining the effect of a range of spironolactone doses $(25-100 \mathrm{mg} / \mathrm{kg} \mathrm{s.c.}$.) on basal and acute stress-induced corticosterone secretion. The dose of $100 \mathrm{mg} / \mathrm{kg}$ was found to significantly increase basal concentrations of corticosterone without affecting corticosterone secretion during restraint stress (data not shown). Spironolactone was also dissolved in propylene glycol and administered s.c. $(1 \mathrm{ml} / \mathrm{kg})$. All antagonist injections were administered $1 \mathrm{~h}$ prior to subsequent treatment (restraint or $\mathrm{CRH}$ injections).

\section{Restraint stress}

Restraint stress consisted of placing rats, for $1 \mathrm{~h}$, in well ventilated adjustable length cylindrical plexiglas tubes $(6.3 \mathrm{~cm}$ diameter and $15.5+2.5 \mathrm{~cm}$ length). Restrained rats were placed on a table top in a room adjacent to the rat's home-cage room. Rats that were given repeated restraint were restrained once a day at the same time each day. Restraint may be considered an example of a psychological or processive stressor in which the triggering of a stress response results from the situation (of being trapped in the tube) rather than a result of direct noxious stimuli (20).

Experiments 1-5: Effect of corticosteroid receptor antagonists on the expression of habituation.

Experiment 1

The first experiment used a combined within and between subjects design to examine whether acute treatment with the combined MR and GR antagonist cocktail has an effect on the expression of habituation as determined by corticosterone secretion. For the within subjects component of the experiment, all rats $(n=12)$ were restrained daily for 6 consecutive days. On the days 1,5 , and 6 of restraint, blood samples were taken immediately after the onset of restraint (determination of basal corticosterone levels), 30 and $60 \mathrm{~min}$ into restraint (determination of stress-induced corticosterone levels), and $1 \mathrm{~h}$ after the termination of restraint (assessment of recovery from restraint). For the 
between subjects component of the experiment, rats were randomly divided into two groups $(n=6)$ that on day 6 of restraint were either pretreated with the combined MR and GR antagonist cocktail or vehicle.

\section{Experiments 2-5}

These experiments used a $2 \times 2$ (restraint experience $\times$ drug condition) between groups design $(n=8)$ to examine the effect of acute corticosteroid receptor antagonist treatment or vehicle treatment on the corticosterone response to restraint in rats either experiencing restraint for the first time or rats that had five previous daily exposures to restraint. For the second experiment, blood samples were taken immediately after the onset of restraint, 15, 30 and $60 \mathrm{~min}$ into restraint, and $1 \mathrm{~h}$ after the termination of restraint. For this experiment, there were unusually high corticosterone levels at the recovery time-point. Due to concerns about the potentially cumulative stress of restraint and frequent serial blood samples, subsequent experiments did not include the $15 \mathrm{~min}$ timepoint.

\section{Experiment 6: $C R H$ challenge}

This experiment investigated the possibility that (i) habituation of the corticosterone response to stress is due to decreased responsiveness of the pituitary to $\mathrm{CRH}$, and (ii) that blockade of the expression of habituation by corticosteroid receptor antagonists was a result of disinhibition of the pituitary's response to CRH. The effects of combined MR and GR antagonists (RU28318 and RU40555) on the corticosterone response to a challenge dose of $\mathrm{CRH}$ or vehicle were examined in control rats or rats that had received restraint stress on the 5 previous days. Thus, on the test day, control rats or previously restrained rats were challenged with vehicle or $\mathrm{CRH}$ after pretreatment with vehicle or the combined $\mathrm{MR}$ and GR antagonist $(2 \times 2 \times 2$ design $)$. Rats were not restrained on the test day except momentarily for blood sample. Pretreatment injections of either the combined MR and GR antagonists or vehicle were administered $1 \mathrm{~h}$ prior to the $\mathrm{CRH} /$ vehicle challenge. An exogenous CRH challenge was administered by i.p. injection of $\mathrm{CRH}(3.0 \mu \mathrm{g} / \mathrm{kg}$; human $/ \mathrm{rat}$ synthetic corticotropin releasing factor from Sigma, St Louis, MO, USA; freshly dissolved in sterile sodium chloride). A $\mathrm{CRH}$ challenge dose that produces an intermediate corticosterone response was selected based on a previous study (21). Blood samples were taken 60 min after the $\mathrm{CRH} /$ vehicle challenge.

\section{Blood sampling procedure}

All blood samples were obtained from the tail vein while the rat was in a Plexiglas tube. For the first sample of the session, the tip of the tail was clipped with a razor blade. Approximately $100-300 \mu \mathrm{l}$ of blood was collected into heparinized polypropylene tubes, and resulting plasma was then stored at $-20^{\circ} \mathrm{C}$. On each blood sample occassion, blood samples were collected from all animals within approximately four minutes after experimenter entry into the animal room.

\section{Corticosterone assay}

Plasma corticosterone was measured by radioimmunoassay. Plasma samples $(20 \mu \mathrm{l})$ were diluted 50 fold in $0.01 \mathrm{M}$ PBS and then heated for $1 \mathrm{~h}$ at $70^{\circ} \mathrm{C}$ to inactivate corticosteroid binding globulin. Samples $(100 \mu \mathrm{l})$ and standards (25-2000 pg/tube) were incubated overnight with $\left[{ }^{3} \mathrm{H}\right]$-corticosterone (20 000 c.p.m.; New England Nuclear, MA, USA) and rabbit antiserum raised against corticosterone-3-oxime BSA (B3-163; Endocrine Sciences, Calabasas Hills, CA, USA). Antibody-bound corticosterone was separated from free corticosterone by mixing with dextran-coated activated charcoal followed by centrifugation. Radioactivity in the resulting supernatant was then measured with a Packard liquid scintillation analyser. Assay sensitivity was $0.5 \mu \mathrm{g} / 100 \mathrm{ml}$. The within-and between-assay coefficients of variation for both a low level of corticosterone $(5 \mu \mathrm{g} / 100 \mathrm{ml})$ and a moderately high level of corticosterone $(20 \mu \mathrm{g} / 100 \mathrm{ml})$ are routinely less than $10 \%$ in our laboratory.

\section{Statistical analysis}

Overall treatment effects were determined in each experiment by the appropriate multiway analysis of variance (ANOVA). In experiment 1 , the corticosterone responses measured on day 1 and day 5 were analysed by a $2 \times 4$ repeated measure ANOvA (day $\times$ stress-test time-point). Day 6 data was analysed by a $2 \times 4$ mixed design ANOVA (drug condition $\times$ stress-test timepoint). Post-hoc comparisons for a given time-point across days used a repeated-measure Student's $t$-test, whereas post-hoc comparisons between groups for a given time-point on day 6 used a between groups Student's t-test. In experiments $2-5$, corticosterone values were analysed with an initial $2 \times 2 \times 4$ (or $2 \times 2 \times 5$ for experiment 2) mixed-design ANOvA (restraint experience $\times$ drug condition $\times$ stress-test time-point). In experiment 6 , values were analysed with an initial $2 \times 2 \times 2$ between groups ANOVA (restraint experience $\times$ antagonist pretreatment $\times \mathrm{CRH}$ challenge). In all experiments, there was an overall significant effect of stress on corticosterone concentrations across the stress-test time-points. Post-hoc analysis examined differences between groups at each time-point using Fisher's least significant difference test. Data presented in the tables and figures are group means \pm SEM.

\section{Results}

Experiment 1: Within and between groups comparison of the effect of combined $M R$ and $G R$ antagonists $(R U 28318+R U 40555)$ on the expression of habituation.

There was a significant habituation of the corticosterone response to restraint stress on day 5 compared to day 1 $[F(1,11)=23.1, P=0.001]$ (Fig. 1). Student's dependent t-tests indicated that the $30 \mathrm{~min}$ time-point during the stress-test on day 5 was significantly lower than the 30 min time-point on day $1(\mathrm{P}<0.01)$. The vehicle pretreatment on day 6 may have partially interfered with the expression of habituation since the vehicle-treated rats had a greater corticosterone response during the 30-min time-point on day 6 than they had on day 5 (Student's depentent $t$-test, $\mathrm{P}<0.05$ ). MR and GR blockade on day 6 produced a large increase in plasma corticosterone levels at the 30 and $60 \mathrm{~min}$ time-points compared to the response on the previous day (Student's dependent t-test, $P<0.01)$. In addition, the corticosterone response on day 6 of drug-treated rats was also significantly greater than their response on day 1 when comparing the $60 \mathrm{~min}$ time-points (Student's dependent t-test, $\mathrm{P}=0.05$ ). Finally, the corticosterone response of the drug treated rats was significantly greater than that of the vehicle treated rats for the 30 and 60 min timepoints (repeated measure) on day $6[\mathrm{~F}(1,10)=16.3, \mathrm{P}=0.002]$.

\section{Experiment 2: Between groups comparison of the effect of combined MR and GR antagonists (RU28318+RU40555) on the expression of habituation}

Although in experiment 1 drug treatment appeared to completely block the expression of habituation, there was not a direct comparison examining the effect that MR and GR blockade has on corticosterone levels in rats exposed to restraint stress for the first time. Thus, the second experiment used a between groups design to examine the effect of MR and GR blockade in rats that were exposed to restraint stress for either the first time or for the sixth time.

Repeated restraint stress produced a significant habituation of the corticosterone response to restraint (Fig. 2). This was supported statistically by comparing the response of vehicletreated rats exposed to restraint for the first time or the sixth time $[F(1,14)=5.7, P=0.032]$. Post-hoc analysis indicated that the repeated-restraint/vehicle group had significantly lower corticosterone levels than the single-restraint/vehicle group at the 15 and $60 \mathrm{~min}$ time-points $(\mathrm{P}<0.05$, Fisher's least significant difference). Acute treatment of rats with MR and GR antagonists increased basal corticosterone levels and completely blocked the expression of habituation. Thus, 
repeated-restraint rats that were pretreated with drug had significantly higher corticosterone levels at every time-point than repeated-restraint rats treated with vehicle. Drug treatment also produced a trend for an increase in corticosterone levels of rats exposed to restraint for the first time. Consequently, there was an overall effect of drug $[\mathrm{F}(1,28)=14.7, \mathrm{P}=0.001]$, and only a trend for a drug by restraint experience interaction $[\mathrm{F}(1,28)=2.6, \mathrm{P}=0.115]$. It is noteworthy, however, that the corticosterone response of repeated-restraint rats treated with $\mathrm{MR}$ and GR antagonists was just as high as the response of single-restraint rats treated with the antagonists.

Experiment 3: Between groups comparison of the effect of glucocorticoid receptor antagonist (RU40555) on the expression of habituation

In the third experiment, repeated restraint stress also produced a significant habituation of the corticosterone response to restraint $[\mathrm{F}(1,14)=8.6, \mathrm{P}=0.011]$ (Fig. 3). Pretreatment with the GR antagonist did not interfere with the expression of habituation, nor did it have an effect on rats that were restrained for the first time.

\section{Experiment 4: Between groups comparison of the effect of mineralocorticoid receptor antagonist ( $R U 28318)$ on the expression of habituation}

Again, repeated restraint stress produced a significant habituation of the corticosterone response to restraint $[\mathrm{F}(1,14)=9.3, \mathrm{P}=0.009]$ (Fig. 4). Acute pretreatment of rats with the MR antagonist RU28318 produced a small increase in basal corticosterone levels that did not reach statistical significance $[\mathrm{F}(1,28)=3.8, \mathrm{P}=0.060]$. RU28318 treatment completely blocked the expression of habituation. Thus, repeated-restraint rats that were pretreated with drug had significantly higher corticosterone levels at the 30 and $60 \mathrm{~min}$ time-points than repeated-restraint rats treated with vehicle ( $\mathrm{P}<0.05$, Fisher's least significant difference). Drug treatment also produced a trend for an increase in corticosterone levels of rats exposed to restraint for the first time. Consequently, there was an overall effect of $\operatorname{drug}[\mathrm{F}(1,28)=15.4, \mathrm{P}=0.001]$, and only a trend for a drug by restraint experience interaction $[F(1,28)=2.4, P=0.133]$. As in experiment 2 , it is noteworthy, however, that the corticosterone response of repeatedrestraint rats treated with the MR antagonist was just as high as the response of single-restraint rats treated with the antagonist.
Day 1 and day 5

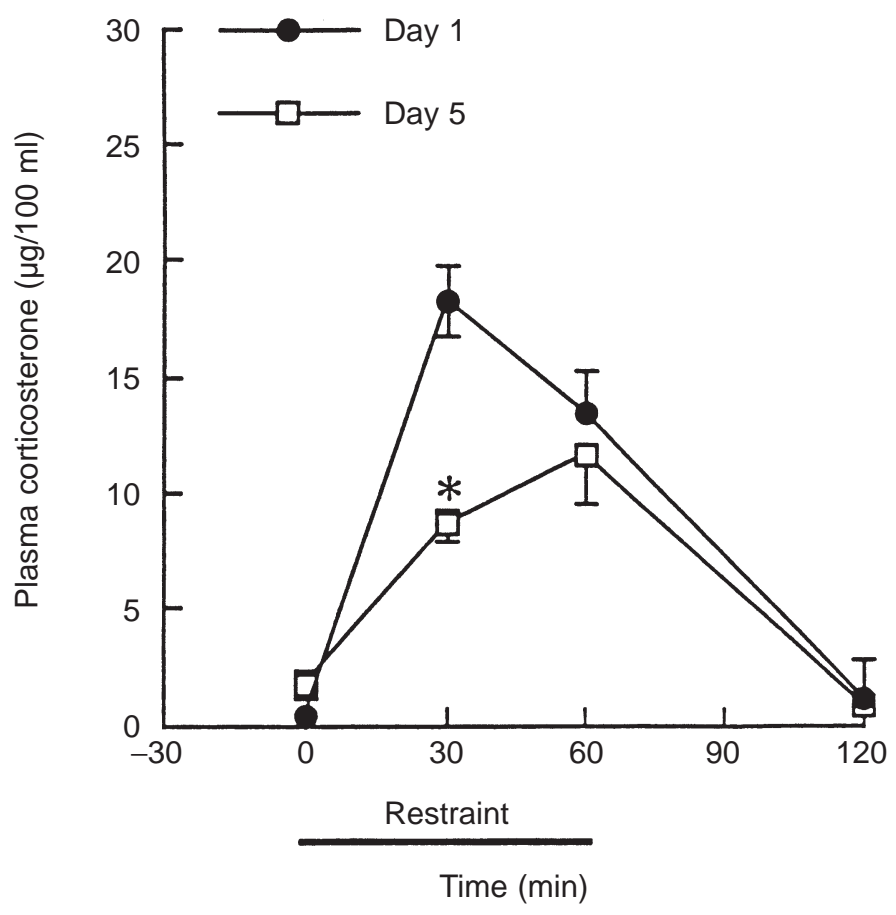

Day 6

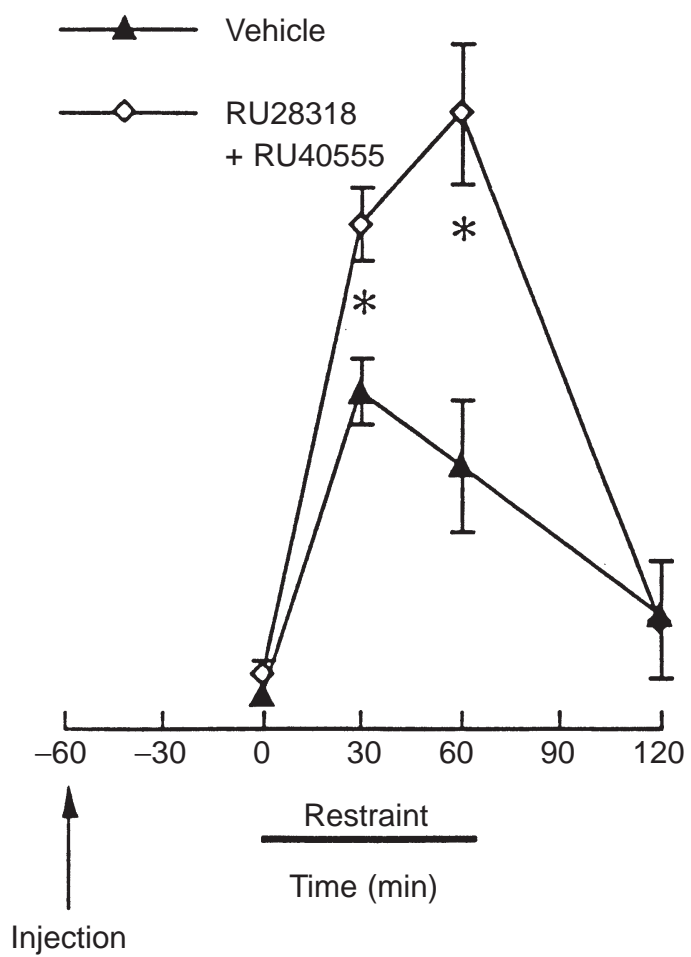

FIG. 1. Corticosterone response to six daily restraint stress sessions with combined mineralocorticoid receptor (MR) and glucocorticoid receptor (GR) antagonist treatment before the sixth session. Rats were restrained for $1 \mathrm{~h}$ on six consecutive days. On day 6 , rats were injected s.c. with a combined MR and GR antagonist $(50 \mathrm{mg} / \mathrm{kg}$ RU28318 $+30 \mathrm{mg} / \mathrm{kg} \mathrm{RU} 40555)$ or vehicle ( $3 \mathrm{ml} / \mathrm{kg}$ propylene glycol) $1 \mathrm{~h}$ prior to restraint stress. Blood samples were taken before ( $0 \mathrm{~min})$, during (30 and $60 \mathrm{~min})$ and $1 \mathrm{~h}$ after $(120 \mathrm{~min})$ restraint on days 1,5 and 6 ; ${ }^{*} \mathrm{P}<0.05$, vs vehicle group at same time-point on same day, Student's t-test. The left panel shows the corticosterone response of all rats on day 1 and day $5(\mathrm{n}=12)$. The right panel shows the corticosterone response of rats on day 6 after vehicle or drug pretreatment $(n=6)$. 
1038 Mineralocorticoid receptor antagonists block habituation expression

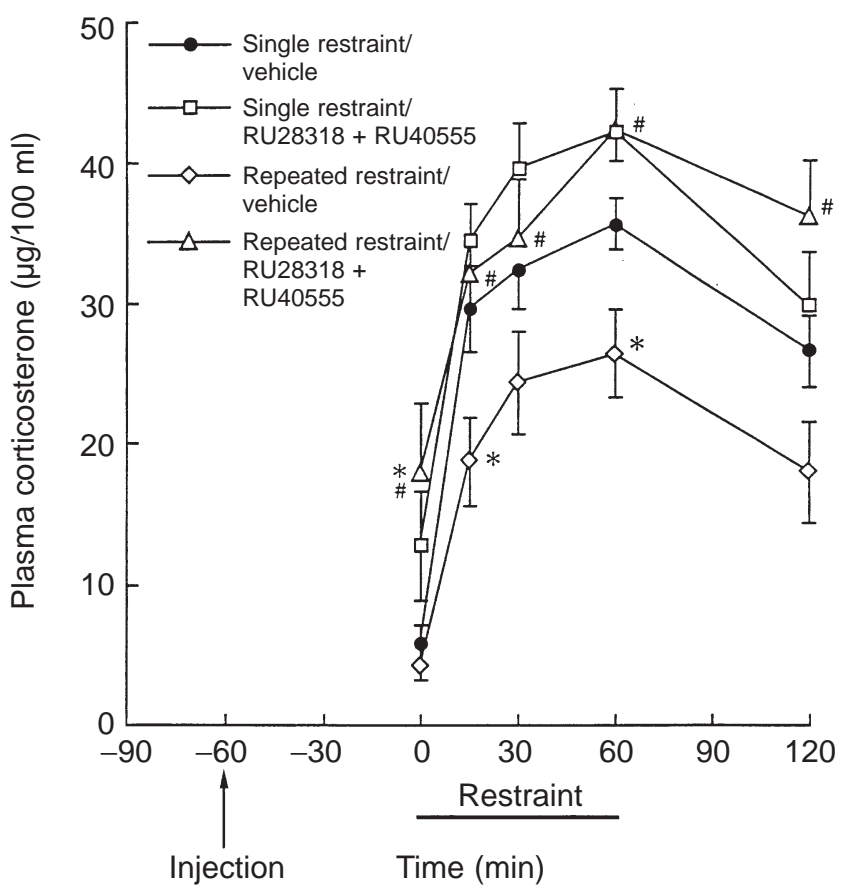

FIG. 2. Corticosterone response to restraint in restraint-naive or repeatedly restrained rats with or without combined mineralocorticoid receptor (MR) and glucocorticoid receptor (GR) antagonist pretreatment. Half of the rats were restrained for $1 \mathrm{~h}$ on five consecutive days (Repeated Restraint) and the other half were homecage controls (Single Restraint). On day 6, all rats were injected s.c. with either $50 \mathrm{mg} / \mathrm{kg}$ RU28318 $+30 \mathrm{mg} / \mathrm{kg}$ RU40555 or vehicle ( $3 \mathrm{ml} / \mathrm{kg}$ propylene glycol) $1 \mathrm{~h}$ before restraint stress. Blood samples were taken before, during and $1 \mathrm{~h}$ after restraint on day $6(\mathrm{n}=8)$; ${ }^{*} \mathrm{P}<0.05$, vs Single Restraint/Vehicle group at the same time-point, Fisher's least significant difference test. \#P $<0.05$, Repeated Restraint/RU28318+RU40555 vs Repeated Restraint/Vehicle group at same time-point, Fisher's least significant difference test.

Experiment 5: Between groups comparison of the effect of a different mineralocorticoid receptor antagonist

(spironolactone) on the expression of habituation

The fifth experiment was conducted to see if acute treatment with a different MR antagonist (spironolactone) would also be sufficient to block the expression of corticosterone habituation. The pattern of results for corticosterone levels in this experiment was similar to that in experiment 4; however, the magnitude of the corticosterone response habituation was less pronounced and did not reach statistical significance $[\mathrm{F}(1,14)=3.4, \mathrm{P}=0.085](\mathrm{Fig} .5)$. There was an overall effect for spironolactone to increase corticosterone levels $[\mathrm{F}(1,28)=6.7, \mathrm{P}=0.015]$. Spironolactone produced a small, but significant increase in basal corticosterone levels ( 0 time-point, $\mathrm{P}<0.05$, Fisher's least significant difference). At the other time-points spironolactone produced a larger increase in corticosterone levels, but these effects did not reach statistical significance (P-values ranging from 0.07-0.10). Importantly, consistent with experiment 4 , there was no trend for an expression of habituation in rats that were acutely treated with the MR antagonist spironolactone.

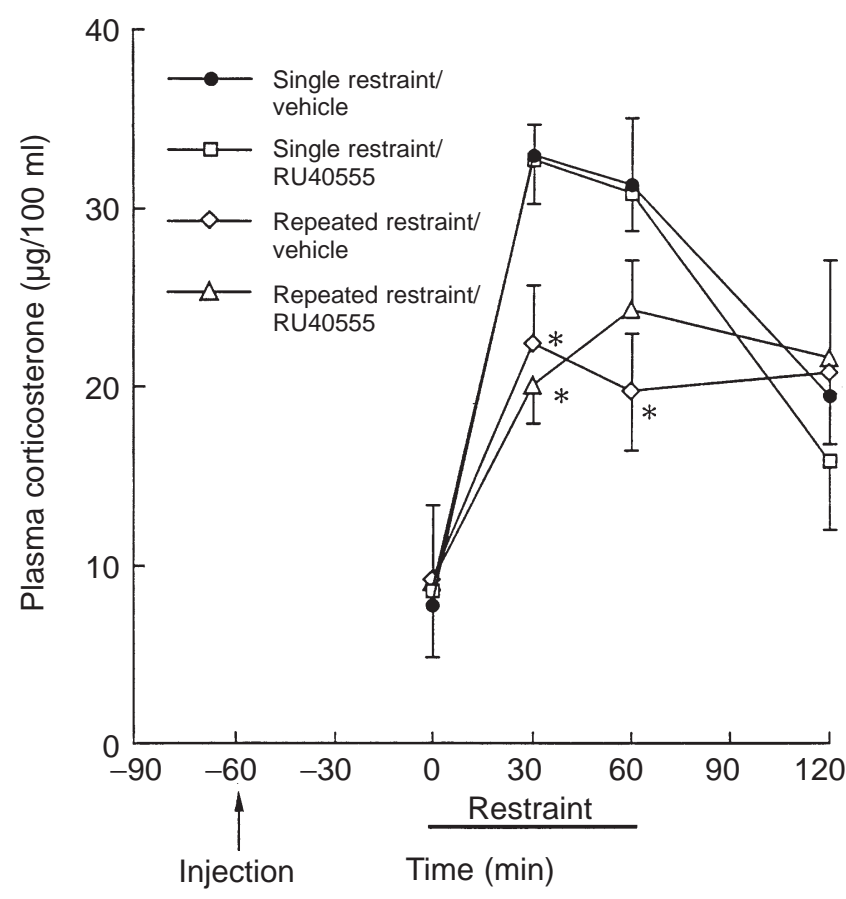

FIG. 3. Corticosterone response to restraint in restraint-naive or repeatedly restrained rats with or without glucocorticoid receptor (GR) antagonist pretreatment. Half of the rats were restrained for $1 \mathrm{~h}$ on five consecutive days (Repeated Restraint) and the other half were home cage controls (Single Restraint). On day 6, all rats were injected s.c. with RU40555 (30 mg/kg) or vehicle $(3 \mathrm{ml} / \mathrm{kg}$ propylene glycol) $1 \mathrm{~h}$ before restraint stress. Blood samples were taken before, during and $1 \mathrm{~h}$ after restraint on day $6(\mathrm{n}=8) ;{ }^{*} \mathrm{P}<0.05$, vs Single Restraint/Vehicle group at the same time-point, Fisher's least significant difference test.

\section{Experiment 6: Between groups comparison of the effect of combined $M R$ and $G R$ antagonists (RU28318+RU40555) on the corticosterone response to a $C R H$ challenge}

$\mathrm{CRH}$ injections produced an overall significant increase in plasma corticosterone levels $[\mathrm{F}(1,39)=57.32, \quad \mathrm{P}<0.001]$ (Fig. 6). However, there was no significant difference in the corticosterone response to $\mathrm{CRH}$ in control vs repeatedrestraint rats. There was a small, but overall significant increase in corticosterone levels of all groups pretreated with the MR and GR combined antagonists $[\mathrm{F}(1,40)=6.53$, $\mathrm{P}=0.015]$. However, post-hoc tests revealed no significant differences between any antagonist $v s$ vehicle comparison for the same previous restraint experience and vehicle/CRH treatment.

\section{Discussion}

\section{HPA axis habituation}

These studies demonstrated a robust habituation of the corticosterone response to repeated restraint stress that was evident by the fifth daily restraint stress session. Habituation of the corticosterone response to restraint has been found in many (22-25), but not all studies $(26,27)$. The decreased corticosterone response to repeated restraint probably reflects a habituated response throughout the entire HPA axis. 


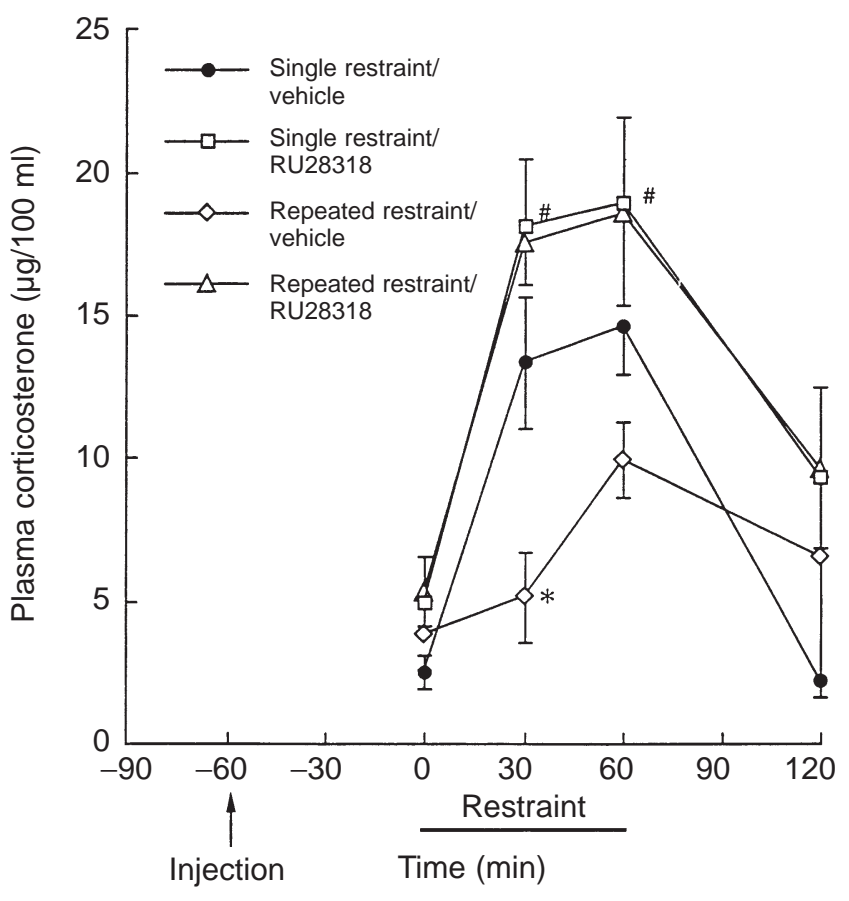

FIG. 4. Corticosterone response to restraint in restraint-naive or repeatedly restrained rats with our without mineralocorticoid receptor (MR) antagonist (RU28318) pretreatment. Half of the rats were restrained for $1 \mathrm{~h}$ on five consecutive days (Repeated Restraint) and the other half were homecage controls (Single Restraint). On day 6, all rats were injected s.c. with RU28318 (50 mg/kg) or vehicle ( $3 \mathrm{ml} / \mathrm{kg}$ propylene glycol) $1 \mathrm{~h}$ before restraint stress. Blood samples were taken before, during and $1 \mathrm{~h}$ after restraint on day $6(\mathrm{n}=8) ;{ }^{*} \mathrm{P}<0.05$, vs Single Restraint/Vehicle group at the same time-point, Fisher's least significant difference test. $\# \mathrm{P}<0.05$, Repeated Restraint/RU28312 vs Repeated Restraint/Vehicle group at same time-point, Fisher's least significant difference test.

Another study has found habituation of ACTH responses to repeated restraint stress (corticosterone was not measured) (28).

Habituation of the HPA axis response must be a result of either altered neural input to the axis, or an altered response of the axis to neural input. In this study, there was no difference in the corticosterone response to a CRH challenge between restraint-naive or restraint-habituated rats. Thus, habituation of the corticosterone response to restraint appears to be the result of changes at the level of the paraventricular nucleus of the hypothalamus or elsewhere in the brain, and expression of this habituation appears to depend on corticosteroid negative feedback.

\section{Dependence of habituation expression on glucocorticoid negative feedback}

We have found in a previous study that the HPA axis response of a rat encountering restraint for the first time is constrained by corticosteroid negative feedback (13). In that study, acute treatment with the combined $\mathrm{MR}$ and GR antagonists produced an elevated plasma corticosterone and ACTH response during $1 \mathrm{~h}$ of restraint. In the present study, we examined the possibility that there is a similar dependence of a habituated HPA axis response on corticosteroid negative

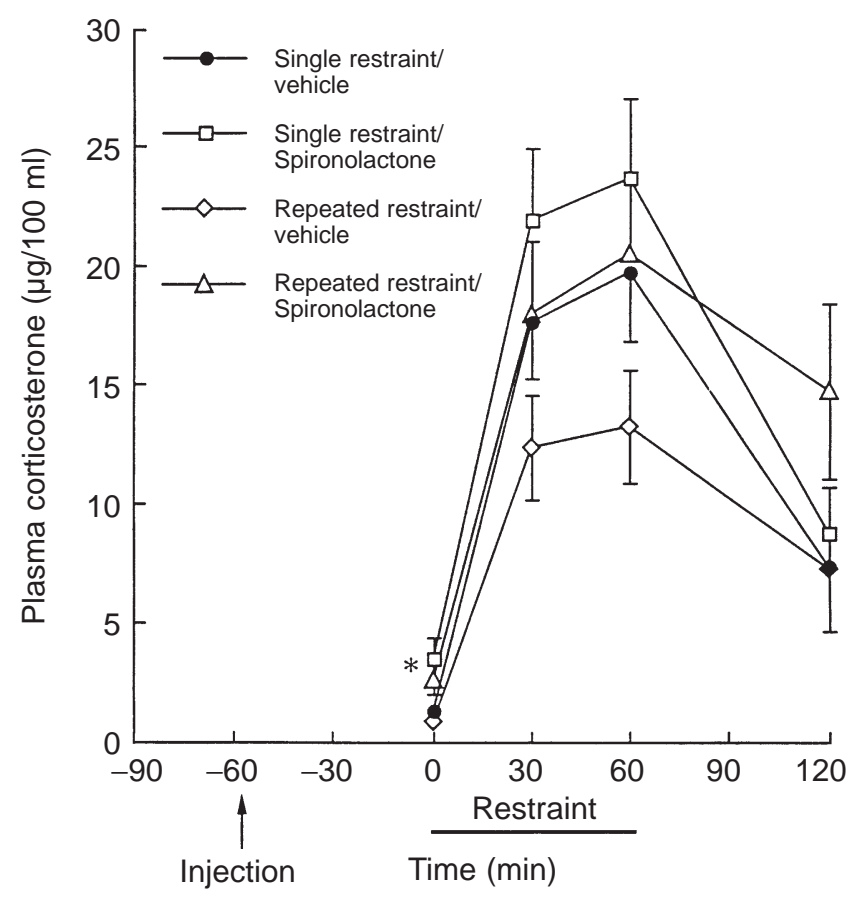

FIG. 5. Corticosterone response to restraint in restraint-naive or repeatedly restrained rats with or without mineralocorticoid receptor (MR) antagonist (spironolactone) pretreatment. Half of the rats were restrained for $1 \mathrm{~h}$ on five consecutive days (Repeated Restraint) and the other half were homecage controls (Single Restraint). On day 6, all rats were injected s.c. with spironolactone $(100 \mathrm{mg} / \mathrm{kg})$ or vehicle $(3 \mathrm{ml} / \mathrm{kg}$ propylene glycol) $1 \mathrm{~h}$ before restraint stress. Blood samples were taken before, during and $1 \mathrm{~h}$ after restraint on day $6(\mathrm{n}=8) ;{ }^{*} \mathrm{P}<0.05$, vs Single Restraint/Vehicle group at the same time-point, Fisher's least significant difference test.

feedback. In experiment 1 , we found that the combined MR and GR antagonist treatment on day 6 prevented the expression of habituation which was evident in the absence of drug treatment on day 5. Interestingly, the corticosterone response of those drug treated rats on day 6 was even greater than it was on day 1 . Experiment 1 did not include a direct comparison of the effect that the combined MR and GR antagonists have on the corticosterone response in rats encountering restraint for the first time. If the HPA axis response normally reflects the net influence of stimulatory drive and glucocorticoid negative feedback, then removal of glucocorticoid negative feedback by pretreatment with MR and GR antagonists results in unopposed stimulatory drive. One possibility, as discussed above, is that habituation involves a decreased stimulatory input to the HPA axis. If so, blocking negative feedback should not prevent the expression of habituation. Contrary to this prediction, we found in experiment 2 that the corticosterone response to restraint was the same in restraint-naive or restrainthabituated rats pretreated with the combined MR and GR antagonists.

The similar HPA axis response to restraint of naive and habituated rats when pretreated with corticosteroid receptor antagonists does not appear to be the result of a ceiling effect of maximal HPA axis disinhibition. The maximum corticosterone concentrations in experiment $2-5$, although variable, 


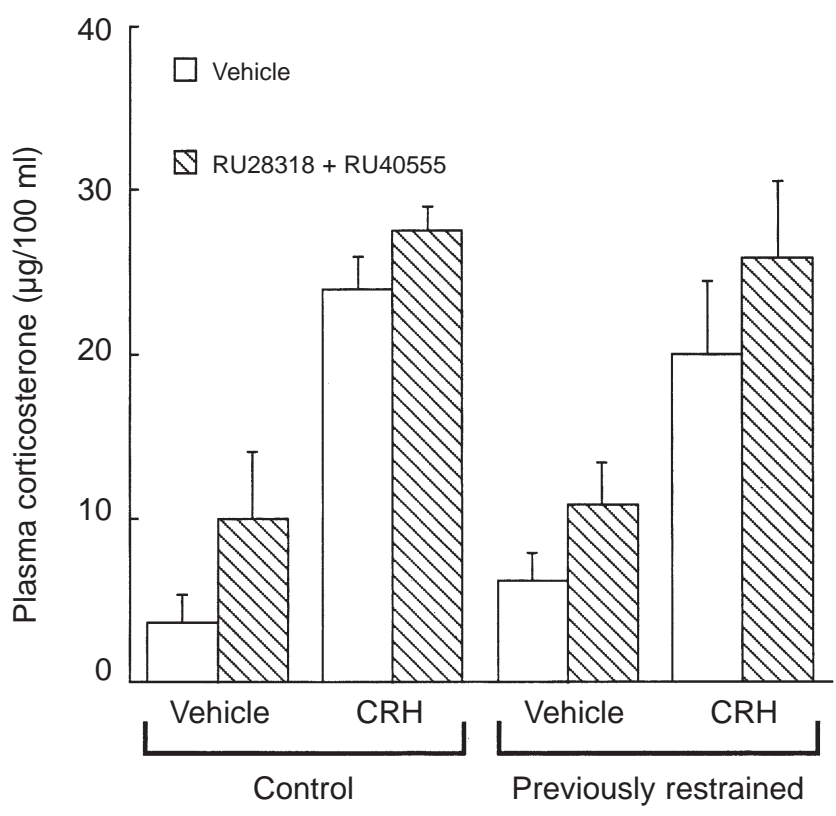

Treatments

FIG. 6. Effect of combined mineralocorticoid receptor (MR) and glucocorticoid receptor (GR) blockade on the corticosterone response to a $\mathrm{CRH}$ challenge in rats that were previously restrained or homecage controls. Testing for all rats took place the day after the last (fifth) restraint session of the repeatedly restrained group. Rats were first injected s.c. with either RU28318 (50 mg/kg) + RU40555 (30 mg/kg) or vehicle ( $3 \mathrm{ml} / \mathrm{kg}$ propylene glycol), and then $1 \mathrm{~h}$ later received an i.p. CRH $(3.0 \mu \mathrm{g} / \mathrm{kg})$ or vehicle $(0.25 \mathrm{ml}$ saline $)$ injection $(\mathrm{n}=6)$. Blood samples were taken $60 \mathrm{~min}$ after $\mathrm{CRH} /$ vehicle injections. There was an overall significant effect of $\mathrm{CRH}$, and an overall significant effect of corticosteroid antagonist treatment. However, none of the post-hoc comparisons between antagonist or vehicle pretreated groups with the same restraint experience and $\mathrm{CRH} / \mathrm{vehicle}$ challenge were significant.

are all substantially less than the maximal values (approximately $60 \mu \mathrm{g} / 100 \mathrm{ml}$ corticosterone) that we see in this strain of rats (our unpublished observations). Thus, based on the magnitude of drug-induced habituation reversal observed in the present study, it would appear that the expression of habituation is completely dependent on corticosteroid negative feedback. On the other hand, there is some reason to believe from other published studies that a decreased stimulatory input to the HPA axis is a component of stress habituation. Several studies report a habituation of c-fos gene expression with repeated restraint in the paraventricular nucleus of the hypothalamus, as well as in other stressresponsive brain regions $(24,29,30)$. In addition, habituation of c-fos gene induction has been observed in adrenalectomized rats (24). This would indicate that habituation of the HPA axis response is a result of decreased stimulatory activity throughout stress-responsive brain regions. Further studies will be necessary to resolve this apparent paradox.

\section{Blockade of MR but not GR is sufficient to prevent expression of habituation}

In a previous study, we found that pretreatment of restraint naive rats with either the MR or GR antagonist alone was not able to significantly disinhibit the corticosterone response to restraint (13). We concluded from our previous study that suppression of the HPA axis during acute stress is dependent on GR mediated corticosterone negative feedback, but that this feedback is facilitated by corticosterone actions at MR. In the present study, we reexamined the effect of administering the MR or GR antagonists alone on the corticosterone response to restraint of rats habituated to restraint stress. Surprisingly, we found that treatment with the MR antagonist alone was sufficient to block the expression of habituation.

Prevailing models of glucocorticoid regulation of HPA axis activity assign to MR predominantly a role for tonic regulation of basal HPA axis activity $(8,15)$. However, several recent studies provide evidence for MR involvement in regulating stress responses $(11,13,31)$. The general argument for a lack of MR involvement in regulating phasic HPA axis activity during stress responses stems from the notion that the majority of MR are occupied at all times because of their high affinity for corticosterone (7). Our results raise the interesting prospect that the MR antagonist treatment is able to disinhibit the HPA axis during acute stress by blocking a small stress-induced increase in MR occupancy. Alternativly, HPA axis disinhibition may be a result of the substantial reduction in total MR occupancy that occurs after drug injection and before the onset of stress. Reconsideration of basal MR occupancy rates or the primary tonic as opposed to phasic nature of MR mediated corticosterone regulation of HPA axis activity may be warranted.

\section{Site of action for MR-dependent regulation of the expression of habituation}

There is very little evidence for MR expression within the paraventricular nucleus as determined by MR mRNA levels or protein-immunoreactivty (32-34). Thus, corticosterone regulation of the expression of habituation via $\mathrm{MR}$ is most likely to be a result of corticosterone actions outside of the paraventricular nucleus. There is some expression of MR within the pituitary (10). However, under normal conditions, other studies suggest that there may be very little corticosterone negative feedback at the pituitary due to the strong buffering capacity of high local concentrations of corticosteroid binding globulin (18). This conclusion is consistent with our $\mathrm{CRH}$ challenge studies that found no difference in the corticosterone response to $\mathrm{CRH}$ in restraint-naive or restraint-habituated rats pretreated with the combined MR and GR antagonist compared to vehicle pretreatment. It should be noted, however, that several studies have found an increase in stress-induced vasopressin expression in parvocellular paraventricular nucleus neurones after repeated restraint stress $(23,35)$. It is possible that acute corticosteroid receptor antagonist treatment blocks a selective inhibitory effect of corticosterone on corticotrope sensitivity to vasopressin. Nevertheless, it is more likely that MR located in the brain are responsible for the blockade of the expression of habituation after treatment with MR antagonists. Possible candidate brain regions for an MR-dependent inhibition of the HPA axis are the hippocampus, septum and frontal cortex (20). A recent study found that microinjection of the MR 
antagonist RU28318 into the hippocampus of rats increased circadian peak basal corticosterone concentrations (36).

\section{Habituation and a shift in the dependence of the HPA axis on MR mediated corticosteroid negative feedback}

One possible explanation for a greater effectiveness of MR antagonist treatment in restraint-habituated rats than in restraint-naive rats is that there is less occupancy of GR during restraint in habituated rats. In restraint-naive rats, the large corticosterone response to the first experience of restraint stress may produce sufficient GR occupancy to compensate for the MR blockade. Thus, MR-dependent corticosterone negative feedback may only help to constrain HPA axis responses when the overall magnitude of the response is relatively small.

On the other hand, our results may reflect a more generalized increased sensitivity of the HPA axis to MR mediated corticosterone negative feedback that is produced by repeated restraint. Reul and colleagues recently found that one session of acute stress (swim stress) produced a significant increase in hippocampal MR $24 \mathrm{~h}$ later, and that this increase in MR was correlated with a greater effect of RU28318 treatment on basal corticosterone levels (37). An experiment by van den Berg et al. (38) also suggests a shift in MR dependency in repeatedly restrained rats. In that study, brief restraint produced an increase in arterial pressure that was unaffected by pretreatment with RU28318. However, MR antagonist pretreatment suppressed this pressor response after the rats had been exposed for 2 weeks to the daily condition of restraint stress and hyperthermia. An increased dependency of the HPA axis on MR-mediated corticosteroid negative feedback during habituation may play a protective role during repeated stress by minimizing the extent to which the brain is exposed to potentially deleterious effects of excess corticosteroids $(39,40)$.

\section{Acknowledgements}

This work was supported by NIH Grants MH-54742 and DK-49143, and the University of Colorado Undergraduate Research Opportunity Program.

\section{Accepted 4 May 2000}

\section{References}

1 McCarty R, Gold PE. Catecholamines, stress, and disease: a psychobiological perspective. Psychosomatic Med 1996; 58: 590-597.

2 Pitman DL, Ottenweller JE, Natelson BH. Effect of stressor intensity on habituation and sensitization of glucocorticoid responses in rats. Behav Neurosci 1990; 104: 28-36.

3 Dhabhar FS, McEwen BS, Spencer RL. Adaptation to prolonged or repeated stress-comparison between rat strains showing intrinsic differences in reactivity to acute stress. Neuroendocrinology 1997; 65: $360-368$.

4 Kalman BA, Kim PJ, Cole MA, Chi MS, Spencer RL. Diazepam attenuation of restraint stress-induced corticosterone levels is enhanced by prior exposure to repeated restraint. Psychoneuroendocrinology 1997; 22: $349-360$.

5 Arriza JL, Weinberger C, Cerelli G, Glaser TM, Handelin BL, Housman DE, Evans RM. Cloning of human mineralocorticoid receptor complementary DNA. Structural and functional kinship with the glucocorticoid receptor. Science 1987; 237: 268-275.

6 Hollenberg SM, Weinberger C, Ong ES, Cerelli G, Oro A, Lebo R,
Thompson EB, Rosenfeld MG, Evans RM. Primary structure and expression of a functional human glucocorticoid receptor cDNA. Nature 1985; 318: 635-641.

7 Reul JHMH, de Kloet ER. Two receptor systems for corticosterone in rat brain: microdistribution and differential occupation. Endocrinology 1985; 117: 2505-2511.

8 Dallman MF, Arkana SF, Cascio CS, Darlington DN, Jacobson L, Levin N. Regulation of ACTH secretion: variations on a theme of B. Rec Prog Horm Res 1987; 43: 113-173.

9 Spencer RL, Young EA, Choo PH, McEwen BS. Adrenal steroid type I and type II receptor binding: estimates of in vivo receptor number, occupancy, and activation with varying levels of steroid. Brain Res 1990; 514: $37-48$.

10 Spencer RL, Miller AH, Moday H, Stein M, McEwen BS. Diurnal differences in basal and acute stress levels of type I and type II adrenal steroid receptor activation in neural and immune tissues. Endocrinology 1993; 133: 1941-1950.

11 Ratka A, Sutanto W, Bloemers M, de Kloet ER. On the role of brain mineralocorticoid (type I) and glucocorticoid (type II) receptors in neuroendocrine regulation. Neuroendocrinology 1989; 50: 117-123.

12 Weidenfeld J, Feldman S. Glucocorticoid feedback regulation of adrenocortical responses to neural stimuli: role of CRF-41 and corticosteroid type I and type II receptors. Neuroendocrinology 1993; 58: $49-56$.

13 Spencer RL, Kim PJ, Kalman BA, Cole MA. Evidence for mineralocorticoid receptor facilitation of glucocorticoid receptor-dependent regulation of hypothalamic-pituitary-adrenal axis activity. Endocrinology 1998; 139: 2718-2726.

14 Kim PJ, Cole MA, Kalman BA, Spencer RL. Evaluation of RU28318 and RU40555 as selective mineralocorticoid receptor and glucocorticoid receptor antagonists, respectively: receptor measures and functional studies. J Ster Biochem Molec Biol 1998; 67: 213-222.

15 DeKloet ER, Oitzl MS, Joels M. Functional implications of brain corticosteroid receptor diversity. Cell Mol Neurobiol 1993; 13: 433-455.

16 Dallman MF, Levin N, Cascio CS, Akana SF, Jacobson L, Kuhn RW. Pharmacological evidence that the inhibition of diurnal adrenocorticotropin secretion by corticosteroids is mediated via type I corticosteronepreferring receptors. Endocrinology 1989; 124: 2844-2850.

17 Bradbury MJ, Akana SF, Dallman MF. Roles of type I and II corticosteroid receptors in regulation of basal activity in the hypothalamo-pituitary-adrenal axis during the diurnal trough and the peak: evidence for a nonadditive effect of combined receptor occupation. Endocrinology 1994; 134: 1286-1296.

18 De Kloet ER, Vreugdenhil E, Oitzl MS, Joels M. Brain corticosteroid receptor balance in health and disease. Endocr Rev 1998; 19: 269-301.

19 Cutler GB, Pita JC, Rifka SM, Menard RH, Sauer MA, Loriaux DL. SC 25152: a potent mineralocorticoid antagonist with reduced affinity for the $5 \alpha$-dihydrotestosterone receptor of human and rat prostate. $J$ Clin Endocrinol Metabol 1978; 47: 171-175.

20 Herman JP, Prewitt CM-F, Cullinan WE. Neuronal circuit regulation of the hypothalamopituitary-adrenocortical stress axis. Crit Rev Neurobiol 1996; 10: 371-394.

21 Cole MA, Kim PJ, Kalman BA, Spencer RL. Dexamethasone suppression of corticosteroid secretion: evaluation of the site of action by receptor measures and functional studies. Psychoneuroendocrinology 2000; 25: 151-167.

22 Keim KL, Sigg EB. Physiological and biochemical concomitants of restraint stress in rats. Pharmacol Biochem Behav 1976; 4: 289-297.

23 Ma X-M, Lightman SL. The arginine vasopressin and corticotrophinreleasing hormone gene transcription responses to varied frequencies of repeated stress in rats. J Physiol 1998; 510: 605-614.

24 Melia KR, Ryabinin AE, Schroeder R, Bloom FE, Wilson MC. Induction and habituation of immediate early gene expression in rat brain by acute and repeated restraint stress. J Neurosci 1994; 14: 5929 5938.

25 Riegle GD. Chronic stress effects on adrenocortical responsiveness in yound and aged rats. Neuroendocrinology 1973; 11: 1-10.

26 Kant GJ, Eggleston T, Landman-Roberts L, Kenion CC, Driver GC, Meyerhoff JL. Habituation to repeated stress is stressor specific. Pharmacol Biochem Behav 1985; 22: 631-634.

27 Pitman DL, Ottenweller JE, Natelson BH. Plasma corticosterone levels during repeated presentation of two intensities of restraint stress: chronic stress and habituation. Phys Behav 1988; 43: 47-55. 
1042 Mineralocorticoid receptor antagonists block habituation expression

28 Campmany L, Pol O, Armario A. The effects of two chronic intermittent stressors on brain monoamines. Pharmacol Biochem Behav 1996; 53: 517 523.

29 Chen X, Herbert J. Regional changes in c-fos expression in the basal forebrain and brainstem during adaptation to repeated stress: correlations with cardiovascular, hypothermic and endocrine responses. Neuroscience 1995; 64: 675-685.

30 Watanabe Y, Stone E, McEwen BS. Induction and habituation of c-fos and zif/268 by acute and repeated stressors. Neuroreport 1994; 5: 1321 1324.

31 Oitzl MS, van Haarst AD, Sutanto W, de Kloet ER. Corticosterone, brain mineralocorticoid receptors (MRs) and the activity of the hypothalamic-pituitary-adrenal (HPA) axis: the Lewis rat as an example of increased central MR capacity and a hyporesponsive HPA axis. Psychoneuroendocrinology 1995; 20: 655-675.

32 Ahima RS, Krozowski Z, Harlan RE. Type I corticosteroid receptor-like immunoreactivity in the rat CNS. Distribution and regulation by corticosteroids. J Comp Neurol 1991; 313: 522-538.

33 Arriza JL, Simerly RB, Swanson LW, Evans RM. The neuronal mineralocorticoid receptor as a mediator of glucocorticoid response. Neuron 1988; 1: 887-900.
34 Herman JP. Regulation of adrenocorticosteroid receptor mRNA expression in the central nervous system. Cell Molec Neurobiol 1993; 13: $349-372$.

35 Ma X-M, Lightman SL, Aguilera G. Vasopressin and corticotropinreleasing hormone gene responses to novel stress in rats adapted to repeated restraint. Endocrinology 1999; 140: 3623-3632.

36 van Haarst AD, Oitzl MS, de Kloet ER. Facilitation of feedback inhibition through blockade of glucocorticoid receptors in the hippocampus. Neurochem Res 1997; 22: 1323-1328.

37 Gesing A, Bilang-Bleuel A, Linthorst ACE, Reul JMHM. Corticotropinreleasing hormone-mediated rise in rat brain mineralocorticoid receptor density following acute stress: functional significance. Soc Neurosci Abs 1999; 25: 707.

38 van den Berg DTWM, de Jong W, de Kloet ER. Mineralocorticoid antagonist inhibits stress-induced blood pressure response after repeated daily warming. Am J Physiol 1994; 267: E921-E926.

39 Sapolsky RM. Glucocorticoids and hippocampal damage. Trends Neurosci 1987; 10: 346-349.

40 Sapolsky RM. Why stress is bad for your brain. Science 1996; 272: 749750 . 